\title{
A Retrospective Analysis of Therapeutic Inertia in Type 2 Diabetes Management Across a Diverse Population of Health Care Organizations in the USA
}

\author{
Cori R. Rattelman (D) - Elizabeth L. Ciemins · Nikita Stempniewicz • \\ Michelle Mocarski · Rahul Ganguly · John K. Cuddeback
}

Received: October 27, 2020 / Accepted: December 23, 2020 / Published online: January 18, 2021

(C) The Author(s) 2021

\section{ABSTRACT}

Introduction: If their target glycated hemoglobin $\left(\mathrm{HbA}_{1 \mathrm{c}}\right)$ is not achieved after 3 months, timely treatment intensification is recommended in people with type 2 diabetes to maintain glycemic control and minimize vascular complications. We retrospectively investigated potential therapeutic inertia in the management of type 2 diabetes in multiple health care organizations across the USA.

Methods: Electronic health records were analyzed from 22 American Medical Group Association (AMGA) health care organizations. Bolus insulin-naïve patients with type 2 diabetes and $\mathrm{HbA}_{1 \mathrm{c}} \geq 8.0 \% \quad(\geq 64 \mathrm{mmol} / \mathrm{mol})$ at baseline were followed for 24 months to identify the frequency and average duration of therapeutic inertia (no new class of glucose-lowering medication prescribed, or not achieving their target $\mathrm{HbA}_{1 \mathrm{c}}[<8.0 \%$; $\left.<64 \mathrm{mmol} / \mathrm{mol}]\right)$.

Supplementary Information The online version contains supplementary material available at https:// doi.org/10.1007/s13300-020-00993-w.

C. R. Rattelman $(\varangle)$. E. L. Ciemins .

N. Stempniewicz $\cdot$ J. K. Cuddeback

AMGA (American Medical Group Association),

Alexandria, VA, USA

e-mail: crattelman@amga.org

M. Mocarski · R. Ganguly

Novo Nordisk Inc., Plainsboro, NJ, USA
Results: The study cohort comprised almost 28,000 patients. Therapeutic inertia was observed in $\approx 50 \%$ of patients after 6 months, and in $>10 \%$ after 24 months. Less therapeutic inertia was observed in patients receiving one or no oral antidiabetic drugs (OADs) (36\% or $28 \%$, respectively, at 6 months), while more inertia was seen following multiple OADs or basal insulin $(54 \%$ of those on baseline basal insulin at 6 months). Although an observable action was recorded for $90 \%$ of patients, many (44\%) had still not achieved their target $\mathrm{HbA}_{1 \mathrm{c}}$ after 24 months.

Conclusion: The results corroborate the presence of therapeutic inertia in people with type 2 diabetes, suggesting that treatment intensification guidelines are not being followed. Extensive variability in the presence of therapeutic inertia was observed both across and within organizations; investigating this further and sharing best practices across providers might help improve the quality of patient care at organizational and national levels.

\section{PLAIN LANGUAGE SUMMARY}

People with type 2 diabetes have their glycated hemoglobin $\left(\mathrm{HbA}_{1 \mathrm{c}}\right)$ level measured regularly by their care provider to check their blood sugar levels over the previous 2-3 months and the diabetes control achieved with their current 
treatment. To keep $\mathrm{HbA}_{1 \mathrm{c}}$ within an individually recommended range, changes to therapies or doses may be needed, which is known as 'treatment intensification.' Despite guidelines describing this best-practice approach, 'therapeutic inertia' (not intensifying treatment when needed) is common. This therapeutic inertia may be a result of complicated or confusing guidelines, a lack of time or awareness/understanding on the part of the health care provider, or patient-specific barriers such as treatment cost or fear of side effects. Due to therapeutic inertia, patients can have poorly controlled diabetes for a long time, increasing their risk of other diabetes-related health problems or complications. This study describes widespread therapeutic inertia in the management of type 2 diabetes across the USA, suggesting that treatment intensification in patients with poor diabetes control is not taking place when needed. Diabetes-related health complications caused by poorly controlled disease over a period of time can significantly reduce quality of life. Diabetes and its complications also increase costs for the health care system due to the resulting medical costs and diabetes-related reductions in productivity. It is important to encourage early diagnosis of diabetes and appropriate and timely treatment. Investigating the variations in therapeutic inertia seen within and between health care organizations and sharing the lessons learned by the top-performing organizations may help spread best practices and improve the quality of patient care.

Keywords: Clinical inertia; Electronic health records; Health system; Integrated delivery network; Therapeutic inertia; Treatment intensification; Type 2 diabetes

\section{Key Summary Points}

\section{Why carry out this study?}

Despite guidelines setting out a bestpractice approach for the management of type 2 diabetes, therapeutic inertia often occurs.

Not intensifying treatment when needed can cause diabetes-related complications, negatively affecting patient quality of life and resulting in additional costs for the health care system.

This study looked at electronic health records from 22 health care organizations to assess the frequency and average duration of therapeutic inertia.

\section{What was learned from the study?}

Therapeutic inertia was observed in $\approx 50 \%$ of patients after 6 months, and in $>10 \%$ after 24 months.

There was extensive variability in therapeutic inertia both within and between organizations.

Investigating therapeutic inertia and sharing lessons learned may help to spread best practices and improve quality of care.

\section{DIGITAL FEATURES}

This article is published with digital features, including a plain language summary and a summary slide, to facilitate understanding of the article. To view digital features for this 
article go to https://doi.org/10.6084/m9. figshare.13476675.

\section{INTRODUCTION}

According to the Centers for Disease Control and Prevention (CDC), an estimated 34.2 million US adults have diabetes, and $90-95 \%$ of these are thought to have type 2 diabetes [1]. The total USA health care expenditure associated with diagnosed diabetes was USD 327 billion in 2017, with USD 237 billion spent on direct medical costs and USD 90 billion lost due to reduced productivity [2]. In high-income countries, a large proportion of the total diabetes expenditure is associated with the treatment of related complications (an estimated $80 \%$ in the United Kingdom) [3, 4]. It is imperative for health care systems to put policies in place for early diagnosis and appropriate and timely treatment to help reduce the complications associated with progression of the disease [5] and the associated ever-increasing demand on health care resources.

In order to meet recommended glycated hemoglobin $\left(\mathrm{HbA}_{1 \mathrm{c}}\right)$ goals, international guidelines produced by the American Diabetes Association (ADA) and the European Association for the Study of Diabetes (EASD) advocate initial treatment with metformin monotherapy (with lifestyle modifications) followed by treatment intensification with the stepwise addition of other glucose-lowering therapies to help achieve glycemic targets and slow type 2 diabetes progression [6-8]. Due to the progressive nature of type 2 diabetes, maintenance of good glycemic control will inevitably require treatment titration or intensification as time goes on [9]. Critically, the ADA emphasizes the importance of timely treatment intensification (additional therapy is recommended if $\mathrm{HbA}_{1 \mathrm{c}}$ target is not achieved after 3 months) [7]. These current guidelines are consistent with ADA recommendations for treatment intensification during the period of observation for this study (January 2015 to June 2017) [10-12].

Therapeutic inertia is the failure to intensify (or deintensify) therapy in patients when appropriate to do so, for example when $\mathrm{HbA}_{1 \mathrm{c}}$ goals are not being met [13]. Therapeutic inertia has been identified at several stages in the diabetes management pathway [14]. In patients with type 2 diabetes, considerable delays in treatment intensification were reported in several UK studies despite suboptimal glycemic control, with a 1.6-year delay in patients treated with one oral antidiabetic drug (OAD) and an approximately 4-year delay in patients treated with basal insulin with or without OADs $[15,16]$. Reasons for therapeutic inertia may include patient-, physician- and system-level barriers [17].

Therapeutic inertia may further contribute to the large proportion of patients with suboptimal glycemic control. This, in turn, increases patients' risk of long-term complications, reducing quality of life and contributing to increased health care expenditure [18]. It is therefore vital for health care systems to identify and overcome therapeutic inertia to help improve the overall management of type 2 diabetes and reduce the total cost of care.

Together $2 \mathrm{Goal}^{\circledR}$ is a national campaign by AMGA (American Medical Group Association) Foundation that challenges participating medical groups and health systems to improve care for 1 million people with type 2 diabetes. Launched in 2016, campaign participants met this goal by 2019 [19], and will continue these efforts through March 2021. This initiative is part of a larger effort by AMGA to help improve quality of care and patient outcomes for chronic conditions that have the greatest impact on quality of life, productivity, and cost for Americans. More than 150 AMGA member organizations have participated in the national campaign, reaching nearly 2 million patients through 61,000 full-time equivalent physicians. As part of the campaign, delayed intensification of treatment was identified as a challenge in this population, and data from a subset of health care organizations were analyzed in this study.

The aim of the present study was to retrospectively identify and describe therapeutic inertia over 6-24 months in the management of type 2 diabetes in a diverse population of health systems across the USA, most of which were participating in the Together $2 \mathrm{Goal}^{\circledR}$ campaign. 


\section{METHODS}

\section{Data Source}

AMGA is a nonprofit trade association representing more than 400 multispecialty medical groups and integrated health care delivery systems with 175,000 full-time equivalent physicians [20]. Optum ${ }^{\mathrm{TM}}$ is AMGA's distinguished data and analytics collaborator, providing access to data for a subset of AMGA members using a population health analytics tool. Members contribute electronic health record (EHR) data to a common data repository. Data are mapped and normalized to allow valid and reliable comparisons. Detailed EHR data enable the identification of differences in care processes as well as clinical outcomes.

From this common data repository that, at the time of this analysis, pooled longitudinal EHR data from 54 health care organizations, including records for approximately 79 million patients, we had access to longitudinal EHR data for 22 of these health care organizations through their membership of AMGA (19 of these groups were participating in the Together 2 Goal $^{\circledR}$ campaign). These data represented a diverse population of health care systems across urban, suburban, and rural locations in 19 USA states.

For this analysis, extracted EHR clinical data included patient demographics (e.g., age, sex, and race/ethnicity), diagnoses, procedures, vital signs, and clinical characteristics (e.g., blood pressure, body mass index [BMI]), laboratory test dates and results (e.g., $\mathrm{HbA}_{1 \mathrm{c}}$ ), prescriptions, health care utilization metrics (e.g., ambulatory office visits and procedures performed), insurance type (e.g., Medicare, Medicaid, commercial and uninsured), and imputed education level and median household income (based on census data and 5-digit zip codes). The data analyzed in this study were collected for routine clinical care, not for research purposes. As such, no ethical committee approvals were required.

\section{Study Design}

We conducted a retrospective descriptive analysis of EHR records across 22 AMGA-member health care organizations. All eligible patients who met the inclusion criteria were followed for a maximum of four consecutive 6-month periods to identify the frequency and average duration of therapeutic inertia (Fig. 1). For this analysis, we defined therapeutic inertia as the proportion of patients with no observable action within $6,12,18$, and 24 months of failure to meet their target. An observable action was defined as: (1) a prescription for a new class of glucose-lowering medication relative to the established baseline medication regimen (regardless of whether the patient met their $\mathrm{HbA}_{1 \mathrm{c}}$ target), or (2) no new prescription but a measured $\mathrm{HbA}_{1 \mathrm{c}}<8.0 \%(<64 \mathrm{mmol} / \mathrm{mol})$ during the 6-month window. For patients who meet criterion (2), we assume that some action was taken by the clinical team that resulted in the patient meeting the target (this might include, for instance, dose titration for an existing class of glucose-lowering medication, nutritional and/or diabetes counseling, or a medication review-actions that are not captured with regularity in EHR structured fields). Patients without an observable action in a 6-month window continued to be observed for the next 6 months. This was repeated until a patient had an observed action, or for a maximum of 24 months (four 6-month intervals). In addition, all eligible patients were followed for the full 24 months post index date to determine the proportion of patients who achieved control and the median time taken to achieve control (number of days from index). Since individualized $\mathrm{HbA}_{1 \mathrm{c}}$ targets are not available in the data, we used a population target of $\mathrm{HbA}_{1 \mathrm{c}}<8.0 \%$ $(<64 \mathrm{mmol} / \mathrm{mol})$ in this analysis. This is consistent with the $\mathrm{HbA}_{1 \mathrm{c}}$ control measure used for the Together $2 \mathrm{Goal}^{\circledR}$ campaign and the Healthcare Effectiveness Data and Information Set (HEDIS) Comprehensive Diabetes Care measure for $\mathrm{HbA}_{1 \mathrm{c}}$ control in patients aged 18-75 years with diabetes [21]. Institutional review board approval was not required for this study. 


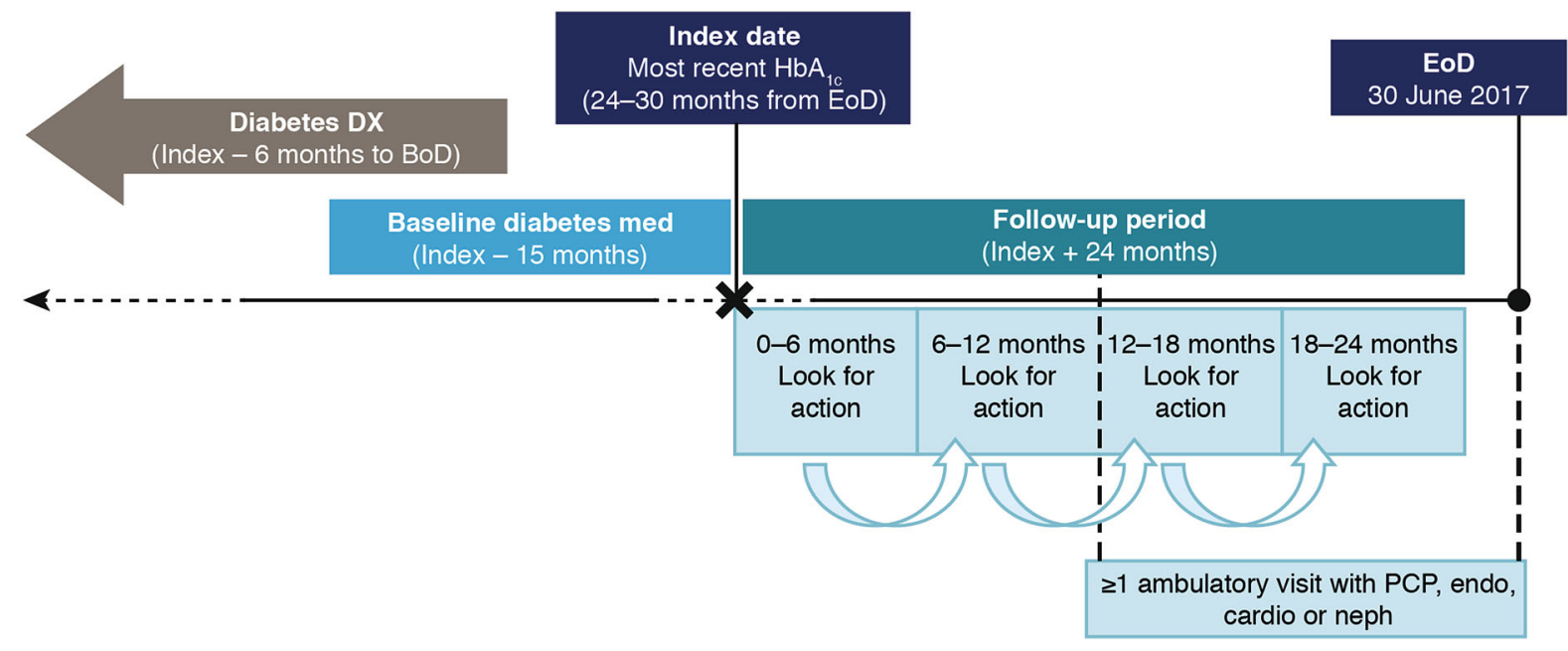

Fig. 1 Study design. $B o D$ beginning of data, cardio cardiologist, $D X$ diagnosis, endo endocrinologist, EoD end of data, $H b A_{1 c}$ glycated hemoglobin, neph nephrologist, $P C P$ primary care provider

\section{Study Population}

To determine inclusion in the analysis, we identified patients who had a $\mathrm{HbA}_{1 \mathrm{c}}$ measurement in the 6-month window 24-30 months from the end of data (January 1, 2015 to June 30, 2015). For patients who met that criterion, the last measured $\mathrm{HbA}_{1 \mathrm{c}}$ of the patient in that window was considered their index $\mathrm{HbA}_{1 \mathrm{c}}$, and the date of that $\mathrm{HbA}_{1 \mathrm{c}}$ measurement was the patient's index date. Patients were included in the analysis if they had an index $\mathrm{HbA}_{1 \mathrm{c}}$; were 18-75 years of age (at index date); had $\geq 1$ ambulatory visit with a primary care, endocrinology, cardiology, or nephrology provider in the last 12 months of data (January 7, 2016 to June 30, 2017); and had a type 2 diabetes diagnosis on an ambulatory claim or patient problem list ( $\geq 6$ months prior to the index date).

Patients were excluded from the analysis if they had died or received hospice care prior to the end of the data; had evidence of type 1 diabetes, chemical-induced diabetes, pregnancy, gestational diabetes, polycystic ovary disease, hemolytic anemia, or chronic blood loss anemia during the 15 months prior to the index $\mathrm{HbA}_{1 \mathrm{c}}$ (baseline period) or the 24-month follow-up study period; or had no baseline activity (inpatient, outpatient, emergency department, laboratory, or prescriptions). To ensure that the final dataset represented a subset of patients for whom we could expect, based on guidelines, to see a clinical or therapeutic action in the 6 months following the index $\mathrm{HbA}_{1 \mathrm{c}}$, patients must have had at least two consecutively recorded $\mathrm{HbA}_{1 \mathrm{c}}$ values $\geq 8.0 \%$ ( $\geq 64 \mathrm{mmol} / \mathrm{mol}$ ) (the most recent being the index $\mathrm{HbA}_{1 \mathrm{c}}$ measure) or an index $\mathrm{HbA}_{1 \mathrm{c}}$ value $\geq 8.0 \%$ and no $\mathrm{HbA}_{1 \mathrm{c}}$ measured in the 15 -month baseline period. Patients were excluded if they used a bolus insulin as part of their treatment regimen, as this is typically a latestage intervention after all other treatment options have been used.

\section{Statistical Analyses}

Results for therapeutic inertia were analyzed overall and stratified by organization (including site and primary care provider level), patient characteristics at index date (age, race, gender, BMI, Charlson Comorbidity Index, Diabetes Complications Severity Index, insurance status, income and education [both imputed at the 5-digit zip-code level], and baseline medication regimen). Diabetes medications (both at baseline and new prescriptions) were specified at the class level and represent intent to treat (prescriptions were ascertained from e-prescribing and medication lists in the EHR; no dispensing 
data were available). Drug classes considered included OADs (biguanides [metformin], sulfonylureas, thiazolidinediones [TZDs], dipeptidyl peptidase-4 inhibitors [DPP-4is], and sodium-glucose cotransporter-2 inhibitors [SGLT-2is]) and injectable antidiabetic agents (glucagon-like peptide-1 receptor agonists [GLP1 RAs], short-acting/mixed insulin [bolus], and long-acting insulin [basal]). The baseline medication regimen was established based on all prescriptions in the 15 months prior to, but not including, the date of the index $\mathrm{HbA}_{1 \mathrm{c}}$. A 15-month medication baseline was determined to allow for a 12-month prescription at $80 \%$ adherence.

Student $t$-tests and chi-squared tests were performed to identify significant differences.

\section{RESULTS}

\section{Population Characteristics}

Across the 22 AMGA health care organizations included in the analysis, approximately 354,000 patients were identified with type 2 diabetes, an index $\mathrm{HbA}_{1 \mathrm{c}}$ 24-30 months before end of data, and $\geq 1$ ambulatory visit with a primary care, endocrinology, cardiology, or nephrology provider in the last 12 months before end of data (see Table S1 in the "Supplementary Information"). Applying the exclusion criteria reduced the cohort to nearly 28,000 bolus insulin-naïve patients with an index $\mathrm{HbA}_{1 \mathrm{c}} \geq 8.0 \%$ and either an additional $\mathrm{HbA}_{1 \mathrm{c}} \geq 8.0 \%(\geq 64 \mathrm{mmol} / \mathrm{mol})$ or no additional $\mathrm{HbA}_{1 \mathrm{c}}$ measurement at all in the 15-month baseline period. This cohort, considered the subset of patients for whom we would most likely expect an action to be taken during the 24-month follow-up period, was included in the analysis. Their baseline characteristics, stratified according to whether or not an observable action was recorded within 24 months of index, are summarized in Table 1. The $P$ values are statistically significant in many instances, but the clinical significance of these differences is less clear, as the absolute differences are small.
Therapeutic Inertia in Bolus Insulin-Naïve Patients with a Baseline $\mathrm{HbA}_{1 \mathrm{c}} \geq \mathbf{8 . 0 \%}$

The percentages of patients who experienced therapeutic inertia are shown in Fig. 2. At 6, 12, 18 , and 24 months following an index $\mathrm{HbA}_{1 \mathrm{c}}$ $\geq 8.0(\geq 64 \mathrm{mmol} / \mathrm{mol})$, the proportion of patients with therapeutic inertia (no observable action) was $46 \%, 27 \%, 17 \%$, and $12 \%$, respectively. Substantial variation was observed in therapeutic inertia between the different health care organizations included in the analysis (Fig. 3). Looking across health care organizations, the proportion of patients with observed therapeutic inertia 6 months after index ranged from $34 \%$ to $54 \%$ (46-66\% of patients were prescribed a new diabetes medication or came into control, i.e., they achieved the $\mathrm{HbA}_{1 \mathrm{c}}$ control measure) (Fig. 3). At the end of 2 years, therapeutic inertia rates (no action) ranged from $7 \%$ to $19 \%$ (Fig. 3). We observed even greater variability across all clinic sites and providers within organizations (see Fig. S1 in the "Supplementary Information").

The proportion of patients with therapeutic inertia over the 24 months following index, stratified according to baseline antidiabetes treatment regimen and race, is shown in Fig. S2 of the "Supplementary Information." After 6 months, therapeutic inertia was $28 \%$ among patients with no diabetes medications in the baseline period, and 36\% among those with one baseline OAD. Therapeutic inertia was greater among patients whose baseline regimen included two or more OADs and/or injectables (GLP$1 \mathrm{RA}$ and/or basal insulin). Among patients receiving baseline basal insulin, we observed that $54 \%$ had therapeutic inertia after 6 months, $35 \%$ after 1 year, and $17 \%$ after 2 years.

Therapeutic inertia at the end of the 6-month follow-up was 50\% among Black/African American patients versus $45 \%$ among White patients. This difference persisted over time (15\% vs $11 \%$ after 24 months) (see Fig. S2 in the "Supplementary Information"). 
Table 1 Baseline characteristics stratified by observable intervention status 24 months after the index date

\begin{tabular}{|c|c|c|c|c|}
\hline & $\begin{array}{l}\text { All } \\
(n=27,925)\end{array}$ & $\begin{array}{l}\text { Action }^{\mathrm{a}} \\
(n=24,717)\end{array}$ & $\begin{array}{l}\text { No action } \\
(n=3208)\end{array}$ & $P$ value \\
\hline Age, mean (SD) & $57.5(10.1)$ & $57.5(10.1)$ & $57.0(10.3)$ & $0.0037^{\mathrm{c}}$ \\
\hline BMI, mean $(\mathrm{SD})$ & $35.2(7.4)$ & $35.3(7.4)$ & $34.5(7.1)$ & $<0.0001^{\mathrm{c}}$ \\
\hline Gender, \% female & 43.4 & 43.2 & 44.9 & $0.0411^{\mathrm{c}}$ \\
\hline Charlson Comorbidity Index, mean (SD) & $1.8(1.8)$ & $1.8(1.8)$ & $1.4(1.6)$ & $<0.0001^{\mathrm{c}}$ \\
\hline Diabetes Complication Severity Index, mean (SD) & $1.7(1.8)$ & $1.7(1.8)$ & $1.4(1.6)$ & $<0.0001^{\mathrm{c}}$ \\
\hline $\begin{array}{l}\text { Percentage in zip code with a bachelor's degree, } \\
\text { mean (SD) }\end{array}$ & $21.8(11.8)$ & $21.8(11.9)$ & $21.5(11.8)$ & 0.0874 \\
\hline \multicolumn{5}{|l|}{ Type of insurance, \% } \\
\hline Commercial (includes age $\geq 65$ years) & 59.9 & 59.8 & 61.4 & 0.0504 \\
\hline Medicare & 28.7 & 29.1 & 26.0 & $0.0001^{\mathrm{c}}$ \\
\hline Medicaid or uninsured & 6.4 & 6.4 & 6.5 & 0.4139 \\
\hline Other, unknown, or missing & 5.0 & 4.8 & 6.2 & $0.0003^{\mathrm{c}}$ \\
\hline \multicolumn{5}{|l|}{ Race, \% } \\
\hline Asian & 1.7 & 1.6 & 2.4 & $0.0005^{\mathrm{c}}$ \\
\hline Black or African American & 11.4 & 11.0 & 14.5 & $<0.0001^{\mathrm{c}}$ \\
\hline White & 80.4 & 81.0 & 75.8 & $<0.0001^{\mathrm{c}}$ \\
\hline Other or unknown & 6.4 & 6.3 & 7.3 & $0.0172^{\mathrm{c}}$ \\
\hline \multicolumn{5}{|l|}{ Treatment regimen, ${ }^{\mathrm{d}} \%$} \\
\hline Basal insulin \pm OADs, GLP-1 RA & 29.6 & 27.9 & 42.9 & $<0.0001^{c}$ \\
\hline GLP-1 RA \pm OADs & 5.5 & 5.7 & 4.2 & $<0.0001^{\mathrm{c}}$ \\
\hline $3+$ OADs & 13.5 & 13.5 & 13.2 & 0.3197 \\
\hline 2 OADs & 24.3 & 24.2 & 24.4 & 0.4017 \\
\hline $1 \mathrm{OAD}$ & 15.8 & 16.6 & 9.6 & $<0.0001^{\mathrm{c}}$ \\
\hline No antidiabetic medication & 11.3 & 12.0 & 5.7 & $<0.0001^{\mathrm{c}}$ \\
\hline \multicolumn{5}{|c|}{ Number of Together 2 Goal $^{\circledR}$ ambulatory visits in 15-month baseline } \\
\hline 0 & 9.5 & 9.9 & 6.2 & $<0.0001^{\mathrm{c}}$ \\
\hline 1 & 11.7 & 11.5 & 12.9 & $0.0101^{c}$ \\
\hline 2 & 14.5 & 14.1 & 17.6 & $<0.0001^{\mathrm{c}}$ \\
\hline 3 & 16.0 & 15.7 & 18.6 & $<0.0001^{\mathrm{c}}$ \\
\hline 4 & 13.6 & 13.6 & 13.4 & 0.3208 \\
\hline $5+$ & 34.7 & 35.1 & 31.2 & $<0.0001^{\mathrm{c}}$ \\
\hline
\end{tabular}


Table 1 continued

$\begin{array}{llll}\text { All } & \text { Action }^{\mathrm{a}} & \text { No action } & \text { b value } \\ (n=27,925) & (n=24,717) & (n=3208)\end{array}$

Number of $H b A_{1 c}$ tests in 15-month baseline

1

2

3

4

$5+$

15.3

15.3

14.6

0.2241

22.2

21.6

26.8

$<0.0001^{\mathrm{c}}$

28.1

27.9

29.3

0.0536

21.4

21.8

18.5

$<0.0001^{\mathrm{c}}$

10.5

10.8

8.9

$0.0005^{\mathrm{c}}$

2.5

2.6

1.9

$0.0099^{\mathrm{c}}$

$D P P-4 i$ dipeptidyl peptidase-4 inhibitor, GLP-1RA glucagon-like peptide-1 receptor agonist, $O A D$ oral antidiabetic drug, $S D$ standard deviation, $S G L T-2 i$ sodium-glucose cotransporter-2 inhibitor, $n$ number of participants

a Action: patients were prescribed a new class of glucose-lowering medication and/or achieved $\mathrm{HbA}_{1 \mathrm{c}}<8.0 \%$ $(<64 \mathrm{mmol} / \mathrm{mol})$ within 24 months of index $\mathrm{HbA}_{\mathrm{cc}}$

${ }^{\mathrm{b}}$ No action (therapeutic inertia): patients did not achieve $\mathrm{HbA}_{1 \mathrm{c}}<8.0 \%(<64 \mathrm{mmol} / \mathrm{mol})$ and were not prescribed a new medication

c A statistically significant change $(P<0.05)$ was observed between action versus no action groups

d OADs included biguanides (metformin), sulfonylureas, thiazolidinediones, DPP-4is, and SGLT-2is

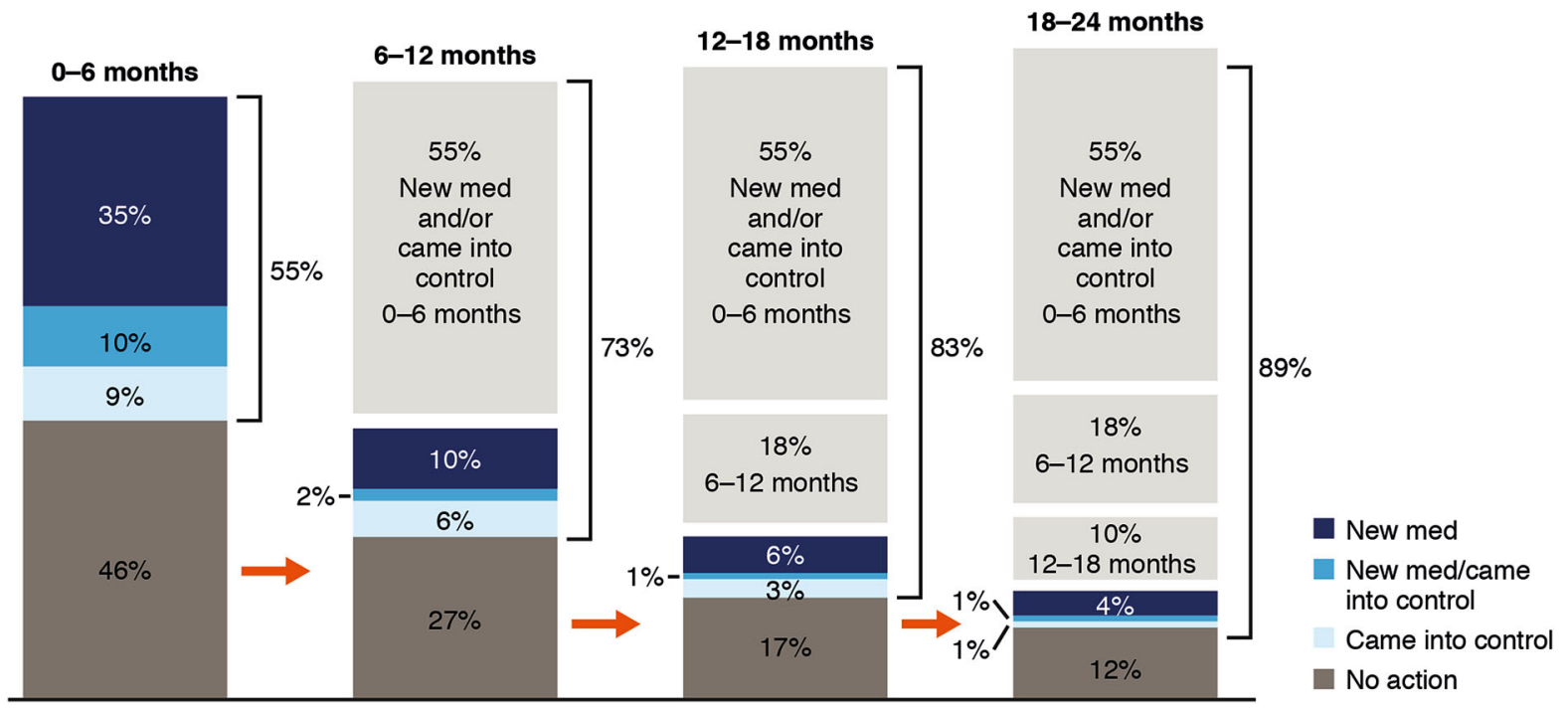

Fig. 2 Therapeutic inertia among bolus insulin-naïve patients with an index $\mathrm{HbA}_{1 \mathrm{c}} \geq 8.0 \%$ over 24 months. Came into control: patients achieved $\mathrm{HbA}_{1 \mathrm{c}}<8.0 \%$ $(<64 \mathrm{mmol} / \mathrm{mol})$ in the time frame specified. New med: patients were prescribed a new class of glucose-lowering medication in the time frame specified. No action (therapeutic inertia): patients did not achieve $\mathrm{HbA}_{\mathrm{lc}}<$ $8.0 \%(<64 \mathrm{mmol} / \mathrm{mol})$ and were not prescribed a new medication. The sum of percentages in some of the followup time periods do not total $100 \%$ due to rounding. $H b A_{1 c}$ glycated hemoglobin 


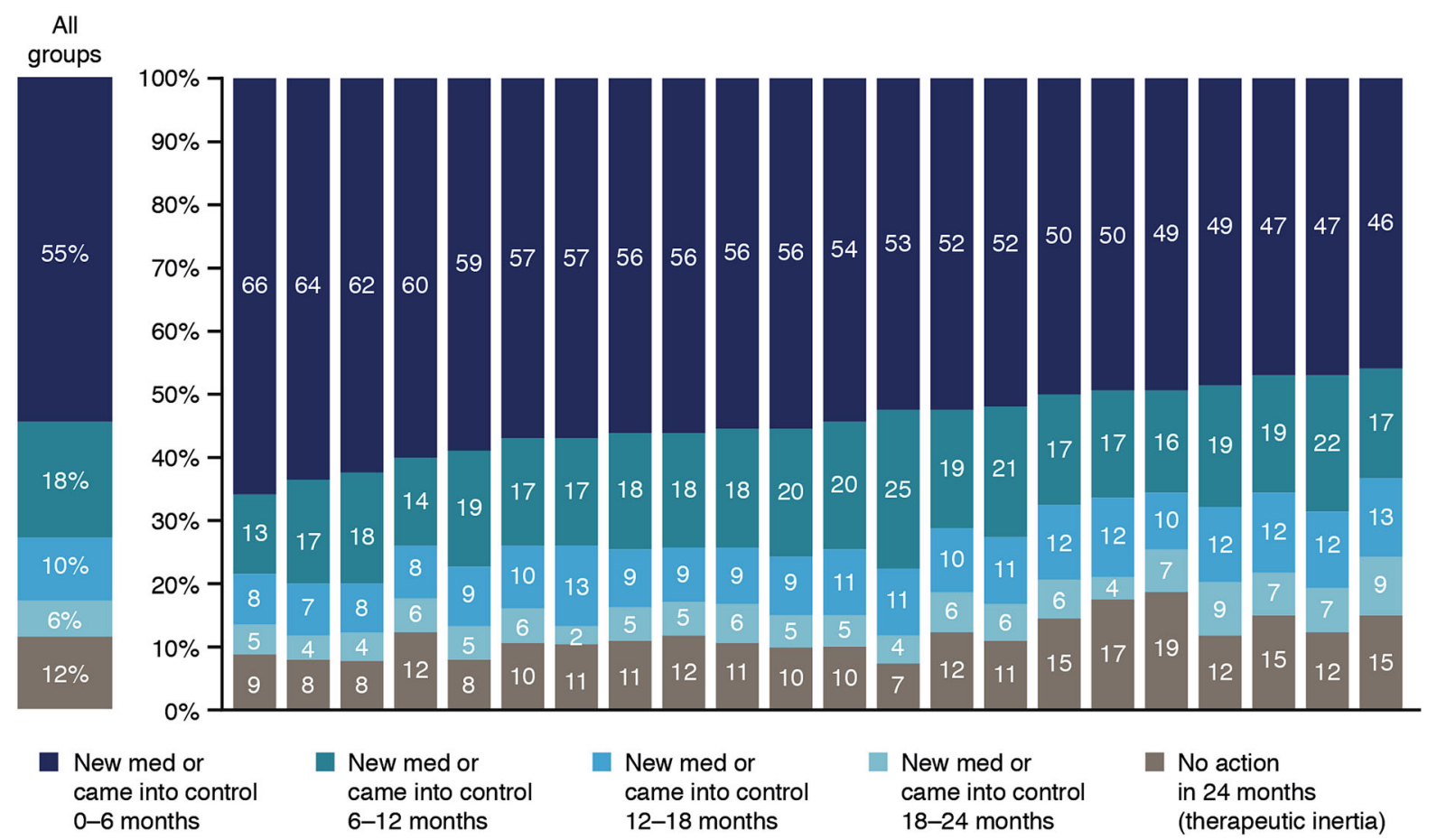

Fig. 3 Therapeutic inertia among bolus insulin-naïve patients with an index $\mathrm{HbA}_{1 \mathrm{c}} \geq 8.0 \%$ over 24 months in each of the participating AMGA health care organizations. Came into control: patients achieved $\mathrm{HbA}_{1 \mathrm{c}}<8.0 \%$ $(<64 \mathrm{mmol} / \mathrm{mol}$ ) between 0 and 24 months from the index date. New med: patients were prescribed a new class of glucose-lowering medication between 0 and 24 months

\section{Proportion of Participants and the Median Time to Achieving $\mathrm{HbA}_{1 \mathrm{c}}<8.0 \%$}

The proportion of patients across all health care organizations who achieved control, $\mathrm{HbA}_{1 \mathrm{c}}<$ $8.0 \%(<64 \mathrm{mmol} / \mathrm{mol})$, at any time within the 24 months following an index $\mathrm{HbA}_{1 \mathrm{c}}$ above target is shown in Fig. S3 of the "Supplementary Information," as is the median time taken to achieve control. Overall, $56 \%(n=15,640)$ of all patients achieved control (range across organizations: 46-66\%), and the median time taken to achieve control was 272 days from index (range across organizations: 180-330 days). Median time to control was shorter for patients receiving only OADs at baseline $(246,266$, and 252 days, respectively, for 1,2 , or $\geq 3$ OADs) compared with those on baseline regimens that included injectable medications (261 days for GLP-1 RA \pm OADs; 289 days for basal insulin \pm from the index date. No action (therapeutic inertia): patients did not achieve $\mathrm{HbA}_{1 \mathrm{c}}<8.0 \%(<64 \mathrm{mmol} / \mathrm{mol})$ and were not prescribed a new medication. The sum of percentages in some of the groups do not total $100 \%$ due to rounding. AMGA American Medical Group Association, $H b A_{1 c}$ glycated hemoglobin

OADs and/or GLP-1 RA), and longer still for those on no baseline antidiabetic medications (293 days).

\section{DISCUSSION}

The ADA recommends a change in therapy if a patient's $\mathrm{HbA}_{1 \mathrm{c}}$ target is not achieved after 3 months [7]. Across 22 USA health care organizations, in bolus insulin-naïve patients with type 2 diabetes and $\mathrm{HbA}_{1 \mathrm{c}} \geq 8.0 \%$ ( $\geq 64 \mathrm{mmol} / \mathrm{mol}$ ), therapeutic inertia (no new class of drug being prescribed or not achieving $\mathrm{HbA}_{1 \mathrm{c}}<8.0 \%$ ) was observed in approximately $50 \%$ of patients after 6 months (ranging from $34 \%$ to $54 \%$ across organizations), more than one-quarter after 12 months, and $>10 \%$ of patients after 24 months (7-19\% across organizations). These findings are of concern and broadly suggest that ADA guidelines are not 
being followed. Delaying the intensification of therapy during the early stages of type 2 diabetes will increase the risk of related complications in these patients, and the associated economic burden [7, 22, 23].

In agreement with previous reports in the literature, less therapeutic inertia was observed in patients receiving one or no OADs, while greater inertia was observed in those patients treated with multiple OADs or basal insulin at baseline. In a retrospective UK study of $>$ 80,000 patients with type 2 diabetes, Khunti and colleagues showed a longer delay to intensify treatment with combination versus monotherapy regimens, specifically a 1.6-year and $>6.9$-year delay in patients with $\mathrm{HbA}_{1 \mathrm{c}}$ $\geq 8.0 \%$ ( $\geq 64 \mathrm{mmol} / \mathrm{mol})$ on one or two OADs, respectively [15]. In a similar study, among patients with type 2 diabetes treated with insulin and eligible for intensification $\left(\mathrm{HbA}_{1 \mathrm{c}}\right.$ $\geq 7.5 \%$ ), only $30.9 \%$ were intensified, with a median time to intensification of 3.7 years [16]. Our study generally corroborates the presence of therapeutic inertia in patients with type 2 diabetes. Therapeutic inertia was particularly prevalent for the first 6 months of suboptimal glycemic control but gradually decreased over the studied 24-month period, although a less prominent decrease was observed in patients using more complex regimens.

Studies have shown that therapeutic inertia was still present during the first 6 months in patients with type 2 diabetes starting basal insulin therapy, even when dose uptitration was considered [24]. Therefore, although the inability to account for dose titration in the data was a limitation of our analysis, it is unlikely to entirely explain the lack of observable actions in patients with persistently uncontrolled type 2 diabetes over the studied 24 months. Those patients receiving basal insulin therapy at baseline are likely to have relatively advanced type 2 diabetes, and the fact that $35 \%$ had $\mathrm{HbA}_{1 \mathrm{c}}$ levels that remained out of control with no new class of glucose-lowering medication prescribed after 1 year, and $17 \%$ after 2 years, is concerning. This suggests a need for further therapeutic intervention in addition to dose uptitration in this population.
After 24 months, an observable action was seen in approximately $90 \%$ of the studied patients; that is, they were prescribed a different treatment or they achieved $\mathrm{HbA}_{1 \mathrm{c}}<8.0 \%$ $(<64 \mathrm{mmol} / \mathrm{mol})$. However, only $56 \%$ of the 28,000 patients followed ever achieved $\mathrm{HbA}_{1 \mathrm{c}}<8.0 \%$ over the 24-month follow-up (median time: 272 days). This finding indicates that, despite treatment intensification over 2 years, patients still have poor glycemic control, so there is an opportunity to further optimize the pharmacologic management of patients with type 2 diabetes. This analysis did not explore treatment patterns following intensification, but further research into the real-world application of type 2 diabetes treatment pathways, as recommended by the ADA [7], would provide insight into where changes in prescription behavior may be warranted.

The $\mathrm{HbA}_{1 \mathrm{c}}$ target of $8.0 \%(64 \mathrm{mmol} / \mathrm{mol})$ used in this analysis to indicate suboptimal glycemic control was the preferred $\mathrm{HbA}_{1 \mathrm{c}}$ threshold chosen by the Together $2 \mathrm{Goal}^{\circledR}$ campaign, as it captured glycemic control across a broad patient population. Other $\mathrm{HbA}_{1 \mathrm{c}}$ targets may be used by health care organizations (including individualized targets), where it is expected that the rate of observed clinical inertia would be greater with more stringent $\mathrm{HbA}_{1 \mathrm{c}}$ targets (e.g., $<7 \%$ [53 $\left.\mathrm{mmol} / \mathrm{mol}\right]$ ) [25].

This was a longitudinal real-world analysis of a large integrated dataset from a diverse population of patients and different types and sizes of health care organizations across urban, suburban, and rural locations in 19 USA states. Unlike previous studies, which presented the average level of therapeutic inertia across the health systems investigated, the present analysis looked at the variation in the level of therapeutic inertia across and within each of the 22 individual AMGA health care organizations investigated, providing insight into where improvements in overcoming therapeutic inertia might be made. Our findings show that, while there is significant variation in therapeutic inertia across health care organizations, there is even greater variation within each organization, at the site level and among providers at those sites. This variation means that, in many cases, organizations have a practice site 
or provider performing at the highest level, from whom others could learn. In turn, each organization has a practice site or provider among the lowest performers, who could benefit from an intervention. This idea of identifying 'high performers' within an organization and sharing lessons learned may be key to overcoming therapeutic inertia [26, 27]. These conversations could also serve to identify the most prevalent underlying reasons for therapeutic inertia.

Other studies of inertia have provided some insight into possible causes. According to Khunti and Davies, reasons for therapeutic inertia include overestimating the care needed when intensifying treatment, using soft reasons to avoid intensification, and a lack of education and training regarding glycemic goal attainment [13]. Some physicians may not have the confidence to intensify treatment by prescribing newer injectable therapies in patients with more advanced diabetes [14]. Physicians may also be reluctant to intensify treatment due to a perception of patient nonadherence [18, 28]. This may explain the greater treatment inertia observed in patients treated with multiple OADs or basal insulin at baseline. Nonadherence to prescribed drug treatments is prevalent among people with diabetes [29]. Patient adherence may be influenced by the complexity and side effects of the treatment, negative media coverage [30, 31], a fear of hypoglycemic episodes and insulin-associated weight gain [14], and poor patient-physician communication [18].

Importantly, health care system-related factors might also influence the prevalence of inertia; these might include a lack of adherence to clinical guidance, no active patient outreach, a lack of screening and referral programs, high medication costs, inadequate cardiovascular risk assessment and risk factor control, inadequate support staff capabilities, and poor internal communication [13, 18]. Addressing these factors at all levels (patient, physician, and health care system) may be key to overcoming clinical and/or therapeutic inertia. Evidence suggests a need for additional patient education around their disease, treatment options, and utilizing available resources, perhaps with more involvement from pharmacists and more opportunities for remote management.

Given the retrospective nature of this analysis, and some specific features of the dataset, there are some limitations to consider. The dataset was biased toward White and commercially insured patients, and toward integrated systems and multispecialty, rather than small independent practices. Furthermore, because AMGA members represent the leading health care providers in terms of quality performance and provision of value-based care, these findings may represent an underestimation of the extent of therapeutic inertia in the broader population. In addition, as data were collected for routine patient management, they were subject to missing values. Data indicating changes in medication dose or lifestyle modifications were not available; nor were pharmacy dispensing data. Therefore, among patients for whom there was no observable clinical action (therapeutic inertia as defined by this study), it is unclear whether their medication dose changed or lifestyle modifications were made. Regardless, many patients had persistently elevated $\mathrm{HbA}_{1 \mathrm{c}}$ levels. Additionally, the study population may not be representative of the USA patient population nor extrapolate easily to other non-USA health care systems or to lowto middle-income countries.

\section{CONCLUSIONS}

In this study, therapeutic inertia observed across a geographically distributed and diverse sample of USA health systems highlighted a need for better adherence to recommended guidelines. Despite a reduction in the observed therapeutic inertia after 24 months, many patients (44\%) were still not achieving their glycemic targets. The greatest degree of inertia was observed in patients further down the treatment path, receiving multiple OADs with or without basal insulin. Investigating the variation in therapeutic inertia seen within and between health care organizations and sharing lessons learned by the top-performing organizations, sites, and providers may help spread 
best practices at both the organizational and national levels.

\section{ACKNOWLEDGEMENTS}

Funding. Novo Nordisk Inc. provided financial support to the Together 2 Goal $^{\circledR}$ campaign and was also the presenting corporate collaborator for the launch of this campaign. Novo Nordisk Inc. also provided funding for medical writing and editing assistance for the development of this manuscript and for the journal's Rapid Service Fee on submission.

Medical Writing and/or Editorial Assistance. The authors are grateful to Jane Blackburn PhD and Helen Marshall, of Watermeadow Medical, an Ashfield company, part of UDG Healthcare plc (funded by Novo Nordisk Inc.), for medical writing and editing assistance.

Authorship. All named authors meet the International Committee of Medical Journal Editors (ICMJE) criteria for authorship for this article, take responsibility for the integrity of the work as a whole, and have given their approval for this version to be published.

Authorship Contributions. CRR led the research, including formulating and refining research questions, planning and conducting all of the analysis, and providing final approval for the manuscript. ELC, JKC, and NS provided input to the research questions, analytical approach, and interpretation of results, and they provided input and critically reviewed and approved the manuscript. MM co-formulated the research question, gave input to the analytical approach, co-interpreted the results, and provided input and approval for the manuscript. RG co-formulated the research question and design.

Prior Presentation. Parts of this study were presented in podium presentation form at the $78^{\text {th }}$ Scientific Sessions of the American Diabetes Association, Orlando, Florida, 22-26 June 2018; in poster form at AcademyHealth's 2018 Annual
Research Meeting (ARM), Seattle, Washington, 24-26 June 2018; and in poster form at AcademyHealth's 2019 Annual Research Meeting (ARM), Washington DC, 2-4 June 2019.

Disclosures. Cori R. Rattelman, Elizabeth L. Ciemins, Nikita Stempniewicz, and John K. Cuddeback have no conflicts of interest to disclose; Rahul Ganguly is an employee of and shareholder of Novo Nordisk Inc.; Michelle Mocarski was an employee and shareholder of Novo Nordisk Inc. at the time of this study and the development of this manuscript (her current affiliation is Bristol Myers Squibb, Lawrence Township, NJ 08648, USA; email: michelle.mocarski@bms.com).

Compliance with Ethics Guidelines. The data analyzed in this study were collected for routine clinical care, not for research purposes. As such, no ethical committee approvals were required.

Data Availability. The datasets generated and/or analyzed during the current study are not publicly available. The data supporting the findings of this study were accessed under a private agreement between Optum and AMGA. Requests for access to the data may be directed to the corresponding author, who will direct the request to an appropriate representative at Optum.

Open Access. This article is licensed under a Creative Commons Attribution-NonCommercial 4.0 International License, which permits any non-commercial use, sharing, adaptation, distribution and reproduction in any medium or format, as long as you give appropriate credit to the original author(s) and the source, provide a link to the Creative Commons licence, and indicate if changes were made. The images or other third party material in this article are included in the article's Creative Commons licence, unless indicated otherwise in a credit line to the material. If material is not included in the article's Creative Commons licence and your intended use is not permitted by statutory regulation or exceeds the permitted use, you will need to obtain permission directly from the 
copyright holder. To view a copy of this licence, visit http://creativecommons.org/licenses/by$\mathrm{nc} / 4.0 /$.

\section{REFERENCES}

1. Centers for Disease Control and Prevention. Diabetes basics. 2020. http://www.cdc.gov/diabetes/ basics/diabetes.html. Accessed 2 Dec 2020.

2. American Diabetes Association. Economic costs of diabetes in the U.S. in 2017. Diabetes Care. 2018;41: 917-28.

3. Ogurtsova $\mathrm{K}$, da Rocha Fernandes JD, Huang Y, et al. IDF Diabetes Atlas: global estimates for the prevalence of diabetes for 2015 and 2040. Diabetes Res Clin Pract. 2017;128:40-50.

4. Diabetes UK. The cost of diabetes. 2014. https:// www.diabetes.org.uk/resources-s3/2017-11/diabet es $\% 20$ uk $\% 20$ cost $\% 20$ of $\% 20$ diabetes $\% 20$ report.pdf. Accessed Apr 2020.

5. Herman WH, Ye W, Griffin SJ, et al. Early detection and treatment of type 2 diabetes reduce cardiovascular morbidity and mortality: a simulation of the results of the Anglo-Danish-Dutch study of intensive treatment in people with screen-detected diabetes in primary care (ADDITION-Europe). Diabetes Care. 2015;38:1449-55.

6. American Diabetes Association. 6. Glycemic targets: standards of medical care in diabetes-2019. Diabetes Care. 2019;42:S61-70.

7. American Diabetes Association. 9. Pharmacologic approaches to glycemic treatment: standards of medical care in diabetes-2019. Diabetes Care. 2019;42:S90-102.

8. Davies MJ, D'Alessio DA, Fradkin J, Management of hyperglycemia in type 2 diabetes, 2018. A consensus report by the American Diabetes Association (ADA) and the European Association for the Study of Diabetes (EASD). Diabetes Care. 2018;41: 2669-701.

9. Fonseca VA. Defining and characterizing the progression of type 2 diabetes. Diabetes Care. 2009;32(Suppl 2):S151-6.

10. American Diabetes Association. 7. Approaches to glycemic treatment. Diabetes Care. 2015;38(Suppl 1):S41-8.
11. American Diabetes Association. 7. Approaches to glycemic treatment. Diabetes Care. 2016;39(Suppl 1):S52-9.

12. American Diabetes Association. Standards of medical care in diabetes-2017. Diabetes Care. 2017;40: S1-135.

13. Khunti K, Davies MJ. Clinical inertia-time to reappraise the terminology? Prim Care Diabetes. 2017;11:105-6.

14. Lovshin JA, Zinman B. Diabetes: clinical inertia-a barrier to effective management of T2DM. Nat Rev Endocrinol. 2013;9:635-6.

15. Khunti K, Wolden ML, Thorsted BL, Andersen M, Davies MJ. Clinical inertia in people with type 2 diabetes: a retrospective cohort study of more than 80,000 people. Diabetes Care. 2013;36:3411-7.

16. Khunti K, Nikolajsen A, Thorsted BL, Andersen M, Davies MJ, Paul SK. Clinical inertia with regard to intensifying therapy in people with type 2 diabetes treated with basal insulin. Diabetes Obes Metab. 2016;18:401-9.

17. Zafar A, Stone MA, Davies MJ, Khunti K. Acknowledging and allocating responsibility for clinical inertia in the management of type 2 diabetes in primary care: a qualitative study. Diabetic Med. 2015;32:407-13.

18. Reach G, Pechtner V, Gentilella R, Corcos A, Ceriello A. Clinical inertia and its impact on treatment intensification in people with type 2 diabetes mellitus. Diabetes Metabol. 2017;43:501-11.

19. AMGA. Together 2 Goal participants achieve improved diabetes care for more than 1 million people nationwide. 2020. http://www.amga.org/ about-amga/amga-newsroom/press-releases/t2g-par ticipants-achieve-improved-diabetes-care-fo/. Accessed Sept 2020.

20. AMGA. About the AMGA family. 2020. http://www. amga.org/about-amga/. Accessed Apr 2020.

21. National Committee for Quality Assurance. Comprehensive Diabetes Care (CDC) HEDIS measures. 2020 . http://www.ncqa.org/hedis/measures/ comprehensive-diabetes-care/. Accessed 30 Jan 2020.

22. Ali SN, Dang-Tan T, Valentine WJ, Hansen BB. Evaluation of the clinical and economic burden of poor glycemic control associated with therapeutic inertia in patients with type 2 diabetes in the United States. Adv Ther. 2020;37:869-82. 
23. Holman RR, Paul SK, Bethel MA, Matthews DR, Neil HA. 10-year follow-up of intensive glucose control in type 2 diabetes. N Engl J Med. 2008;359:1577-89.

24. Mocarski M, Yeaw J, Divino V, et al. Slow titration and delayed intensification of basal insulin among patients with type 2 diabetes. J Manag Care Spec Pharm. 2018;24:390-400.

25. Khunti K, Gomes MB, Pocock S, et al. Therapeutic inertia in the treatment of hyperglycaemia in patients with type 2 diabetes: a systematic review. Diabetes Obes Metab. 2018;20:427-37.

26. Pascale RT, Sternin J, Sternin M. The power of positive deviance: how unlikely innovators solve the world's toughest problems. Boston: Harvard Business Press; 2010.

27. Anderson E, Wiener RS, Resnick K, Elwy AR, Rinne ST. Care coordination for veterans with COPD: a positive deviance study. Am J Manag Care. 2020;26: 63-8.
28. Seal F, Cave AJ, Atkinson LL. Primary non-adherence of prescribed pharmaceutical treatments and interventions: an investigative review to improve quality in primary care. Qual Prim Care. 2017;25: 344-59.

29. Cramer JA. A systematic review of adherence with medications for diabetes. Diabetes Care. 2004;27: 1218-24.

30. Broadbent E, Donkin L, Stroh JC. Illness and treatment perceptions are associated with adherence to medications, diet, and exercise in diabetic patients. Diabetes Care. 2011;34:338-40.

31. García-Pérez LE, Alvarez M, Dilla T, Gil-Guillén V, Orozco-Beltrán D. Adherence to therapies in patients with type 2 diabetes. Diabetes Ther. 2013;4:175-94. 